\title{
Comparative Study of Rivastigmine and Donepezil on Cognitive Function in Mild to Moderate Dementia
}

\author{
Shahnaz Islam¹, Khan Md. Muzammel Hossain², Abul Kalam Mohammed Shoab², \\ Mehedi Hasan ${ }^{4}$, Khaleda Siddika ${ }^{5}$ \\ ${ }^{1}$ Lecturer, Department of Pharmacology, Parkview Medical College, Sylhet, Bangladesh; ${ }^{2}$ Associate Professor, Department of \\ Pharmacology, MAG Osmani Medical College, Sylhet, Bangladesh; ${ }^{3}$ Assistant Professor, Department of Neurology, MAG \\ Osmani Medical College, Sylhet, Bangladesh; ${ }^{4}$ Indoor Medical Officer, Jalalabad Ragib Rabeya Medical College, \\ Sylhet, Bangladesh; ${ }^{5}$ Lecturer, Department of Pharmacology, MAG Osmani Medical College, Sylhet, Bangladesh
}

[Received: 12 October 2018; Accepted: 2 November 2018; Published: 1 January 2019]

\begin{abstract}
Background: Rivastigmine and donepezil are both increase attention and working memory functioning. Objective: The purpose of the present study was to observe and compare the efficacy and safety of rivastigmine and donepezil in mild to moderate dementia. Methodology: This observational study was conducted on patients with mild to moderate dementia attended in the Out-patient Departments of Neurology, Medicine and Psychiatry, Sylhet MAG Osmani Medical College Hospital, Bangladesh during the period from July 2017 to June 2018. Patients with mild to moderate dementia were selected of which group A was treated with rivastigmineand group B was treated with donepezil by respective physician and Mini-Mental State Examination (MMSE) was recorded in all participants before initiation of treatment and at $4^{\text {th }}$ week and at $12^{\text {th }}$ week of treatment. Result: A total of 230 patients with mild to moderate dementia were selected of which 115 were treated with rivastigmine (Group-A) and another 115 were treated with donepezil (Group-B). In course of follow up period 11 patients from group A and 13 patients from group B were dropped out. Finally 104 patients of group-A and 102 patients of group-B were accounted as study subjects for statistical analysis. Out of 230 patients the mean age was $64.89 \pm 6.82$ years and $63.67 \pm 7.02$ in group-A and group-B respectively ( $\mathrm{p}=0.204)$. Vascular dementia was $60(57.7 \%)$ patients and Probable Alzheimer Disease was in 44 $(42.3 \%)$ patients in Rivastigmine treated group. It was $47(46.1 \%)$ and $55(53.9 \%)$ respectively in Donepezil treated group $(\mathrm{p}=0.095)$. The mean duration of dementia was $18.53 \pm 9.25$ months in group-A and $20.82 \pm$ 11.38 months in group-B ( $\mathrm{p}=0.114)$. The changes of mean MMSE score from $14.39 \pm 2.95$ at baseline to $16.37 \pm 3.21$ at $4^{\text {th }}$ week and to $16.37 \pm 3.21$ at $12^{\text {th }}$ week in Rivastigmine treated group $(\mathrm{p}<0.001)$. It was $15.05 \pm 3.49,15.84 \pm 3.86$ and $19.19 \pm 4.38$ respectively in Donepezil treated group at the 12th week $(p<0.001)$. The percentage increment of MMSE score from baseline was $14.29 \%$ at $4^{\text {th }}$ week and $41.43 \%$ at $12^{\text {th }}$ week of treatment in rivastigmine treated group ( $<<0.001$ ). It was $6.29 \%$ and $30.86 \%$ in donepezil treated group $(p<0.001)$. When percentage increment of MMSE score were compared between two treatment group, there were significantly higher percentage increment of MMSE score in rivastigmine treated group compared to donepezil treated group estimated at $4^{\text {th }}$ week $(p<0.001)$ and at $12^{\text {th }}$ week of treatment $(\mathrm{p}=0.001)$. Conclusion: Treatment with rivastigmine and donepezil increases cognitive function by measurement of MMSE in patients with mild to moderate dementia. [Journal of National Institute of Neurosciences Bangladesh, 2019;5(1): 8-12]
\end{abstract}

Keywords: Cognitive Function; Dementia; Rivastigmine; Donepezil

Correspondence: Dr.Shahnaz Islam, Lecturer, Department of Pharmacology, Parkview Medical College, Sylhet, Bangladesh; Email:nipaislam@gmail.com;Cell no.:+8801737053840

Conflict of interest: There is no conflict of interest relevant to this paper to disclose.

Funding agency: This research project was not funded by any group or any institute.

Contribution to authors: SI,HM, MR and MTI involved in protocol preparation, data collection and literature search up to manuscript writing. KMMH involved in preparation and revision of this manuscript.

How to cite this article: Islam S,Hossain KMM, Shoab AKM, Hasan M,Siddika K.Comparative Study of Rivastigmine and Donepezil on Cognitive Function in Mild to Moderate Dementia. J NatIInstNeurosci Bangladesh, 2019; 5(1): 8-12

Copyright: (C2019. Islam et al. Published by Journal of national institute of Neurosciences Bangladesh. This article is published under the creative commons CC-BY- NC License (https://creativecommons.org/licenses/by-nc/4.0/). This license permits use, distribution and reproduction in any medium, provided the original work is properly cited, and is not used for commercial purposes.

\section{Introduction}

Dementia is a clinical syndrome characterized by a loss of previously acquired intellectual function in the absence of impairment of arousal ${ }^{1}$. Today, 46.8 million people worldwide are living with dementia in 2015. This number will almost double every 20 years, reaching 74.7 million in 2030 and 131.5 million in $2050^{2}$. About $3 \%$ of people between the ages of 65-74 have dementia, 19\% 
between 75 and 84 and nearly half of those over 85 years of age ${ }^{3}$. The prevalence of questionable dementia was $11.5 \%$ and definite dementia was $3.6 \%{ }^{4}$.

At the primary and secondary levels of care, simple and brief assessment tools are more appropriate for assessment of severity of dementia, including the Mini-Mental State Examination (MMSE). The MMSE consists of several short cognitive probes, which are administered to the patient only. The results are summarized into a score that ranges from 30 (best) to zero (worst), spanning the spectrum from normal cognition to severe dementia. A large number of studies have demonstrated the reliability and validity of this instrument $^{5}$, with mild cognitive impairment (MMSE scores of 21-26 inclusive), moderate cognitive impairment (MMSE scores of 10-20 inclusive) dementia and severe cognitive impairment MMSE scores of less than $10^{6}$. Reduced levels of Choline-acetyltransferase (ChAT) have been reported in patients with dementia? Other researchers have reported that acetylcholine may have an important role in narrowing the scale of attentional focus ${ }^{8}$.

Acetylcholinesterase Inhibitors (AChEIs) have used as 1 st line treatment for memory problems in patients of dementia. The three common AChEIs available are donepezil, rivastigmine and galantamine. These AChEIs enhance cholinergic transmission by inhibiting acetylcholinesterase Inhibition activity to increase the availability of acetylcholine to interact with postsynaptic acetylcholine receptors. Although they have slightly different modes of action, their clinical efficacy is related primarily to the degree of inhibition. Donepezil is a specific and reversible inhibitor of acetylcholinesterase Inhibitors increasing the levels of synaptic acetylcholine thus improving cognitive functioning 9 .

In contrast, rivastigmine is a pseudo-irreversible inhibitor of both acetylcholinesterase Inhibitors and butyrylcholinersterase (BuChE) inhibitor. Acetylcholinesterase selectively hydrolyses acetylcholine and is found mainly in the brain, whereas butyrylcholinersterase is a non-specific cholinesterase that hydrolyses many different choline-esters including acetylcholine and is found mainly at the periphery. The level of acetylcholinesterase is significantly decreased but that of BuChE increased in dementia patients ${ }^{10}$.This study is designed to observe and compare the effectiveness of rivastigmine and donepezil in the treatment of dementia.

\section{Methodology}

This descriptive type of observational study was conducted in Department of Pharmacology and Therapeutics in collaboration with Department of Neurology, Psychiatry and Medicine, Sylhet MAG Osmani Medical College Hospital, Bangladesh from July 2017 to June 2018 for a period of one year. All patients with mild to moderate dementia attending the outpatient departments of Neurology, Medicine and Psychiatry, fulfilling the inclusion criteria were considered as study population. Convenient consecutive sampling method was applied to select a total 230 sample of mild to moderate dementia of which 115 belonged to rivastigmine (Group-A) and another 115 belonged to donepezil (Group-B) for 12 weeks. Both quantitative and qualitative data were collected in a pre-designed questionnaire. Cognitive function was recorded using MMSE scale by measuring score of baseline, at the end of 4th and 12th week. Socio-demographic data such as age, sex, socio-economic status and educational level were recorded. Safety and tolerability assessments include monitoring and recording of all adverse events were defined as any undesirable sign, symptom or medical condition occurring in course of study period. Quantitative data were expressed as mean and standard deviation and comparison was performed between before and after measurement by paired t test or repeated measure ANOVA and between groups by unpaired $t$ test. Qualitative data were expressed as frequency and percentages and comparison was performed between two groups by Fisher's exact test and Chi-Square test (test of association).Statistical analysis was performed by using SPSS (Statistical package for social science) for windows version 22.0. A probability value (p) of $<0.05$ was considered as significant.

\section{Results}

Two hundred and thirty (230) patients with mild to moderate dementia were selected from which 11 patients from group-A and 13 patients from group-B failed to complete study follow up visit were excluded. So, 104 patients of group-A (rivastigmine treated group) and 102 patients of group-B (donepezil treated group) were analyzed. The age of ranged of rivastigmine treated group was 50 to 80 years; while that of donepezil treated group ranged from 50 to 76 years. Mean \pm SD age of rivastigmine and donepezil treated was $64.89 \pm 6.82$ and $63.67 \pm 7.02$ years respectively. The mean age of the both study groups did not differ significantly suggesting age matching study $(\mathrm{t}=1.274 ; \mathrm{p}=0.204)$. In rivastigmine treated 
group, $36(34.6 \%)$ patients were aged up to 60 years and $68(65.4 \%)$ patients were above 60 years; it was 45 $(44.1 \%)$ and $57(55.9 \%)$ respectively in the donepezil treated group. There was no statistically significant difference between the age group of the patients between two treatment group $\left(\chi^{2}=1.949 ; \quad d f=1\right.$; $\mathrm{p}=0.163)$ (Table 1).

Table 1: Distribution of the patients according to age, sex and duration.

\begin{tabular}{lccc}
\hline Parameters & \multicolumn{2}{c}{ Treated group } & p value \\
\cline { 2 - 3 } & Group A & Group B & \\
\hline Age Group & & & \\
$\leq 60$ years & $36(34.6 \%)$ & $45(44.1 \%)$ & \\
$>60$ years & $68(65.4 \%)$ & $57(55.9 \%)$ & $\dagger 0.163$ \\
Total & $\mathbf{1 0 4}$ & $\mathbf{1 0 2}$ & \\
Mean \pm SD & $64.89 \pm 6.82$ & $63.67 \pm 7.02$ & $* 0.204$ \\
Sex & & & \\
Male & $45(43.3 \%)$ & $56(54.9 \%)$ & \\
Female & $59(56.7 \%)$ & $46(45.1 \%)$ & $\dagger 0.126$ \\
Total & $\mathbf{1 0 4}$ & $\mathbf{1 0 2}$ & \\
Duration in & $18.53 \pm 9.25$ & $20.82 \pm 11.38$ & \\
months & $($ Range 3-48) & $($ range $6-60)$ & 0.114 \\
$($ Mean \pm SD) & & & \\
\hline
\end{tabular}

There were $45(43.3 \%)$ male and $59(56.7 \%)$ female in rivastigmine treated group; whereas $56(53.9 \%)$ male and $46(46.1 \%)$ female in donepezil treated group. The sex of the both study groups did not differ significantly suggesting sex matching study $\left(\chi^{2}=2.339 ; \mathrm{df}=1\right.$; $\mathrm{p}=0.126$ ). The duration of dementia ranged from 3 to 48 months with the mean of $18.53 \pm 9.25$ months in group-A; whereas the duration of dementia in group-B ranged from 6 to 60 months with the mean of $20.82 \pm$ 11.38 months. The duration of dementia in both treatment groups did not differ significantly $(\mathrm{t}=-1.589$; $\mathrm{p}=0.114)$. In the rivastigmine treated group, the mean MMSE score was $14.39 \pm 2.95$ before the initiation of treatment which increased gradually to $16.37 \pm 3.21$ at the 4th week and to $19.95 \pm 3.50$ at the 12 th week. The overall difference from the baseline to the end point of treatment was significant $(\mathrm{F}=284.156 ; \mathrm{df}=2 ; \mathrm{p}<0.001$ ). In the donepezil treated group, the mean MMSE score was $15.05 \pm 3.49$ before the initiation of treatment which increased gradually to $15.84 \pm 3.86$ at the 4 th week and to $19.19 \pm 4.38$ at the 12 th week. The overall difference from the baseline to the end point of treatment was significant $(\mathrm{F}=107.427 ; \mathrm{df}=2 ; \mathrm{p}<0.001)$. When the changes the mean MMSE score were compared between two treatment groups, no significant difference was observed between rivastigmine treated group and donepezil treated group before initiation of treatment $(\mathrm{t}=-1.456 ; \mathrm{p}=0.147)$, at $4^{\text {th }}$ week $(\mathrm{t}=1.056 ; \mathrm{p}=0.292)$ and at $12^{\text {th }}$ week $(\mathrm{t}=1.388$; $\mathrm{p}=0.166)$ (Table 2).

Table 2: Effect of rivastigmine and donepezil on MMSE score administered in patients with dementia estimated at baseline, $4^{\text {th }}$ and $12^{\text {th }}$ week of treatment(Mean \pm SD)

\begin{tabular}{lcccc}
\hline Treated & \multicolumn{3}{c}{ MMSE score } & †pvalue \\
\cline { 2 - 4 } group & At Baseline & At $\mathbf{4}^{\text {th }}$ week & At 12 $^{\text {th }}$ week & \\
\hline Group A & $14.39 \pm 2.95$ & $16.37 \pm 3.21$ & $19.95 \pm 3.50$ & $<0.001$ \\
Group B & $15.05 \pm 3.49$ & $15.84 \pm 3.86$ & $19.19 \pm 4.38$ & $<0.001$ \\
*pvalue & 0.147 & 0.292 & 0.166 & \\
\hline
\end{tabular}

*Unpaired $t$ testand †repeated measure ANOVA was applied to analyze data.

This table also revealed that the reported adverse effects at $12^{\text {th }}$ week of treatment were nausea $(2.9 \%)$, diarrhoea $(2.9 \%)$ and dizziness $(2.9 \%)$ in rivastigmine treated group; while the reported adverse effects were nausea $(2.9 \%)$, vomiting $(2.0 \%)$, diarrhoea $(2.0 \%)$ and dizziness $(3.9 \%)$ in donepezil treated group; the difference was not statistically significant between two treatment groups $(\mathrm{p}=0.779)$.

Table3: Distribution of patients by adverse effect

\begin{tabular}{|c|c|c|c|c|}
\hline \multicolumn{2}{|c|}{ Adverse effect } & GroupA & GroupB & †pvalue \\
\hline \multirow{5}{*}{ 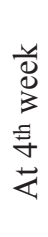 } & Nausea & $12(11.5 \%)$ & $8(7.8 \%)$ & \multirow{5}{*}{0.551} \\
\hline & Vomiting & $3(2.9 \%)$ & $5(4.9 \%)$ & \\
\hline & Diarrhoea & $3(2.9 \%)$ & $6(5.9 \%)$ & \\
\hline & Dizziness & $11(10.6 \%)$ & $7(6.9 \%)$ & \\
\hline & Hypersensitivity & $0(0.0 \%)$ & $0(0.0 \%)$ & \\
\hline \multirow{5}{*}{ 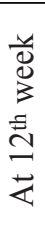 } & Nausea & $3(2.9 \%)$ & $3(2.9 \%)$ & \multirow{5}{*}{0.779} \\
\hline & Vomiting & $0(0.0 \%)$ & $2(2.0 \%)$ & \\
\hline & Diarrhoea & $3(2.9 \%)$ & $2(2.0 \%)$ & \\
\hline & Dizziness & $3(2.9 \%)$ & $4(3.9 \%)$ & \\
\hline & Hypersensitivity & $0(0.0 \%)$ & $0(0.0 \%)$ & \\
\hline
\end{tabular}

*Fisher's Exact test was applied to analyze the data.

\section{Discussion}

Dementia is a syndrome that defies any simple definition; it has become a fear-laden term that encapsulates society's worst terrors. Despite the general lack of consensus about what dementia is in neurological terms, there is agreement that dementia is a long-term medical disability. To this end, there are regular reports in the media and elsewhere concerning the prevalence of the condition.

In this study, the age of the patients ranged from 50 to 80 years with the mean age of $64.89 \pm 6.82$ years in 
rivastigmine treated group; whereas the age of the donepezil treated group ranged from 50 to 76 years with the mean age of $63.67 \pm 7.02$ years. The mean age of the patients did not differ significantly between two treatment groups $(p=0.204)$. This result was nearly similar to the study of parlayan et $\mathrm{al}^{11}$ of which reported the average age for rivastigmine and donepezil groups was $68.9 \pm 8.6$ and $63.5 \pm 6.4$ years old, respectively. In this regards Bullock et $\mathrm{al}^{12}$ found that mean age of the patients with probable Alzheimer's disease was $75.9 \pm$ 6.6 years in rivastigmine treated group and $75.8 \pm 6.8$ years in donepezil treated group. Aguglia et $\mathrm{al}^{13}$ showed mean age of the patients with probable Alzheimer's disease was years $78 \pm 6.4$ years in rivastigmine treated group and $77 \pm 6.47$ years in donepezil treated group. Kazmierski et $\mathrm{al}^{14}$ found the median age of the patients with probable Alzheimer's disease was 76 years in both rivastigmine and donepezil treated groups. The wide range of difference of age may be due to inclusion of probable Alzheimer's disease in those studies. But this study included both probable Alzheimer's disease and vascular dementia. These may be the cause of the difference.

In this study $43.3 \%$ patients were male and $56.7 \%$ patients were female in rivastigmine treated group; whereas $53.9 \%$ patients were male and $46.1 \%$ patients were in donepezil treated group found in the present study. The sex of the patients of rivastigmine treated group and donepezil treated group did not show any statistically significant difference $(p=0.126)$. Kazmierski et $\mathrm{al}^{14}$ found that $38.71 \%$ of patients of rivastigmine treated group were male and $37.72 \%$ of patients of donepezil treated group were male; difference was not significant $(\mathrm{p}=0.74)$. Bullock et al ${ }^{12}$ also showed similar gender distribution of their probable Alzheimer's disease patients that $31.1 \%$ male and $68.9 \%$ female in rivastigmine treated group; and $31.5 \%$ male and $68.5 \%$ female in donepezil treated group. Parlayan et $\mathrm{al}^{11}$ found $50.0 \%$ male and $50.0 \%$ female in rivastigmine treated group; and $40.0 \%$ male and $60.0 \%$ female in donepezil treated group. Aguglia et $\mathrm{al}^{13}$ reported, $34.0 \%$ male and $66.0 \%$ female inrivastigmine treated group and $36.0 \%$ male and $64.0 \%$ female in donepezil treated group.

The duration of dementia in this study ranged from 3 to 48 months with the mean of $18.53 \pm 9.25$ months in rivastigmine treated group; whereas the duration ranged from 3 to 48 months with the mean of $20.82 \pm$ 11.38 months in donepezil treated group. Both treatment groups showed almost similar $(\mathrm{p}=0.114)$ duration. In this regard Bullock et $\mathrm{al}^{12}$ found the duration of dementia was $33.6 \pm 22.2$ months in rivastigmine treated group and $34.2 \pm 26.5$ months in donepezil treated group.

MMSE score was significantly improved at $12^{\text {th }}$ week of treatment $(19.95 \pm 3.50)$ as compared to before treatment $(14.39 \pm 2.95)$ in rivastigmine treated group $(p<0.001)$ was seen in the current study. MMSE score was also significantly improved at $12^{\text {th }}$ week of treatment $(19.19 \pm 4.38)$ as compared to before treatment $(15.05 \pm 3.49)$ in donepezil treated group $(p<0.001)$. This result was in agreement with the study of Abolfazliet $\mathrm{al}^{15}$ that patients taking rivastigmine, a statistically significant improvement $(p=0.007)$ was found in MMSE result after 6 months of treatment. Similarly the patients taking donepezil also showed, a statistically significant improvement $(\mathrm{p}=0.04)$ in MMSE result after same duration of treatment.The present study showed that MMSE score was no significantly differences between rivastigmine and donepezil treated group before staring treatment $(p=0.147)$; at $4^{\text {th }}$ week $(p=0.292)$ and at $12^{\text {th }}$ week $(\mathrm{p}=0.166)$. This result was consistent with the study Abolfazli et $\mathrm{al}^{15}$ that patients received rivastigmine and in patients took donepezil, MMSE score had reached higher score after 6 months but this difference between two drugs in improving MMSE score was not statistically significant. Bullock et $\mathrm{al}^{12}$ and Touchon et $\mathrm{al}^{16}$ also found no significant difference in improving MMSE between rivastigmine and donepezil treated patients. However Caffarra et $\mathrm{al}^{17}$ showed a significant difference between donepezil and rivastigmine treated patients $(p=0.03)$ with rivastigmine treated patients showing greater stability in MMSE scores than the donepezil group.

The present study revealed that the reported adverse effects at $4^{\text {th }}$ week of treatment were nausea $(11.5 \%)$, vomiting $(2.9 \%)$, diarrhoea $(2.9 \%)$ and dizziness $(10.6 \%)$ in rivastigmine treated group; while the reported adverse effects were nausea $(7.8 \%)$, vomiting $(4.9 \%)$,diarrhoea $(5.9 \%)$ and dizziness $(6.9 \%)$ in donepezil treated group; the difference was not statistically significant between two treatment groups $(p=0.551)$.Furthermore the reported adverse effects at $12^{\text {th }}$ week of treatment were nausea $(2.9 \%)$, diarrhoea $(2.9 \%)$ and dizziness $(2.9 \%)$ in rivastigmine treated group; while the reported adverse effects were nausea $(2.9 \%)$, vomiting $(2.0 \%)$, diarrhoea $(2.0 \%)$ and dizziness $(3.9 \%)$ in donepezil treated group; the difference was not statistically significant between two treatment groups $(p=0.779)$. Adverse effects reported in this study were mild and no discontinuation was 
needed. In this regards Aguglia et $\mathrm{al}^{13}$ reported that the most common side effects were gastrointestinal in nature. They found diarrhoea $3(2.4 \%)$ versus $0(0.0 \%)$; nausea $1(0.8 \%)$ versus $1(1.4 \%)$; vomiting $1(0.8 \%)$ versus $0(0.0 \%)$; abdominal pain $0(0.0 \%)$ versus $1(1.4 \%)$; cardiovascular event $2(1.6 \%)$ versus $1(1.4 \%)$; hallucinations $0(0.0 \%)$ versus $1(1.4 \%)$; death while on treatment $3(2.4 \%)$ versus $9(12.8 \%)$ in rivastigmine and donepezil treated patients respectively. But Bullock et $\mathrm{al}^{12}$ found any adverse event $406(82.0 \%)$ versus $323(64.7 \%)$; nausea $163(32.9 \%)$ versus $76(15.2 \%)$; vomiting $138(27.9 \%)$ versus $29(5.8 \%)$; agitation $35(7.1 \%)$ versus $50(10.0 \%)$; anorexia $45(9.1 \%)$ versus 20 (4.0\%); diarrhoea $41(8.3 \%)$ versus $34(6.8 \%)$; weight decreased $30(6.1 \%)$ versus $9(1.8 \%)$; headache $27(5.5 \%)$ versus $23(4.6 \%)$; hypertension $20(4.0 \%)$ versus $7(1.4 \%)$; depression $19(3.8 \%)$ versus $10(2.0 \%)$; in rivastigmine and donepezil treated patients respectively during the titration phase of 1 to 16 weeks. This difference may be due to difference in dose of the drugs they used in their studies.

There are some limitations of this study. As this study was conducted in a single center tertiary hospital and did not represent the actual situation of the country. Sample size was small and duration of treatment period was short due to limitation of time. Only MMSE was employed in this study to assess the efficacy.

\section{Conclusion}

This study demonstrates that both rivastigmine and donepezil treatment appear to offer benefit in the treatment of dementia. But neither rivastigmine nor donepezil showed an advantage over each other on the primary outcome of cognitive function measured by MMSE. Both of these drugs are associated with a small number of side effects which are mild and needs no discontinuation. The differences between the two treatment regimens are not significant. Adverse effects of both treatment groups are not differed significantly.

\section{References}

1. Sharpe MC,Lawrie SM. Medical Psychiatry. In: Walker BR,Colledge NR, Ralston SH and Penman ID.Editors. Davidson's Principles and Practice of Medicine. 22nd ed. Edinburgh: Elsevier, Churchill Livingstone. 2014;250-65

2. Ali MGC,Guerchet M, Wu YT,Prina M. The global prevalence of dementia. In: Prince M, Wimo A, Guerchet M, Ali MGC, Wu YT,Prina M, eds. World Alzheimer Report 2015. The Global Impact of Dementia: An Analysis of Prevalence, Incidence, Cost and Trends. London: Alzheimer's Disease International. 2015; 22
3. Darcy U. Neurological Rehabilitation. 6th ed. St. Louis: Elsevier Mosby. 2012; 838

4. Palmer K, Kabir ZN, Ahmed T, Hamadani JD, Cornelius C, Kivipelto, et al. Prevalence of dementia and factors associated with dementia in rural Bangladesh: Data from a cross-sectional, population-based study. International Psychogeriatr.2014; 26:1905-15

5. Perneczky R, Wagenpfeil S, Komossa K, Grimmer T, Diehl J,Kurz A. Mapping scores onto stages: mini-mental state examination and clinical dementia rating. The American $\mathrm{J}$ of Geriatric Psychiatr.2006; 14(2):139-44

6. Wilkinson DG, Passmore AP, Bullock R,Hopker SW, Smith R, Potocnik FC, et al. A multinational, randomized, 12-week, comparative study of donepezil and rivastigmine in patients with mild to moderate Alzheimer's disease. International J of Clinical Practice. 2002;56:441-46

7. Davis JM, Janicak PG, Hogan DM. Mood stabilizers in the prevention of recurrent affective disorders: a meta-analysis.ActaPsychiatricaScandinavica 1999;100(6):406-17 8. Levy KN, Clarkin JF, Yeomans FE, Scott LN, Wasserman RH, Kernberg OF. The mechanisms of change in the treatment of borderline personality disorder with transference focused psychotherapy. Journal of clinical psychology. 2006;62(4):481-501.

9. Karakaya T, Fuber F, Schröder J,Pantel J. Pharmacological Treatment of Mild Cognitive Impairment as a Prodromal Syndrome of Alzheimer's Disease.Current Neuropharmacology. 2013; 11:102-8

10. Glacobini E. Cholinergic function and Alzheimer's disease. International J of Geriatric Psychiatr. 2003; 18: S1-S5

11. Parlayan E, Yulug B, Bakar M,Gumustas O. Neurometabolic Correlations of Donepezil and Rivastigmine in Dementia Patients: A Different Neuroprotective Effect. The J of Neuropsychiatry and Clinical Neurosciences.2009; 21: 348-49

12. Bullock R, Touchon J, Bergman H, Gambina G, He Y, Rapatz $\mathrm{G}$, et al. Rivastigmine and donepezil treatment in moderate to moderately-severe Alzheimer's disease over a 2-year period. Current Medical Research and Opinion. 2005; 21(8): 1317-27

13. Aguglia E, Onor ML, Saina M,Maso E. An open-label comparative study of rivastigmine, donepezil and galantamine in a real-world setting. Current Medical Research and Opinion. 2004; 20 (11): $1747-52$

14. Kazmierski J, Messini-Zachou C, Gkioka M,Tsolaki M. The Impact of a Long-Term Rivastigmine and Donepezil Treatment on All-Cause Mortality in Patients withAlzheimer's disease. American J of Alzheimer's Disease \& Other Dementias. 2018; 33 : 385-93

15. Abolfazli R, Ghazanshahi S,Nazeman M. Effects of 6-months treatment with donepezil and rivastigmine on results of neuropsychological tests of MMSE, NPI, clock and bender in patients with Alzheimer's disease. Acta MedicaIranica. 2008; 45:101-8

16. Touchon J, Bergman H, Bullock R, Rapatz G, Nagel J, Lane R. Response to rivastigmine or donepezil in Alzheimer's patients with symptoms suggestive of concomitant Lewy body pathology. Current Medical Research and Opinion. 2006; 22: 49-59

17. Caffarra P, Vezzadini G, Copelli S, Dieci F, Messa G, Nonis E, et al. Comparing treatment effects in a clinical sample of patients with probable Alzheimer's disease treated with two different cholinesterase inhibitors. ActaBiomedica. 2007; 78: 16-21 